\title{
Chapter 2 \\ Disorders of Consciousness: Coma, Vegetative and Minimally Conscious States
}

\author{
Olivia Gosseries, Audrey Vanhaudenhuyse, Marie-Aurélie Bruno, \\ Athena Demertzi, Caroline Schnakers, Mélanie M. Boly, Audrey Maudoux, \\ Gustave Moonen, and Steven Laureys
}

\begin{abstract}
Consciousness can be defined by two components: arousal and awareness. Disorders of consciousness (DOC) are characterized by a disrupted relationship between these two components. Coma is described by the absence of arousal and, hence, of awareness whereas the vegetative state is defined by recovery of arousal in the absence of any sign of awareness. In the minimally conscious state, patients show preserved arousal level and exhibit discernible but fluctuating signs of awareness. The study of DOC offers unique insights to the neural correlates of consciousness. We here review the challenges posed by the clinical examination of DOC patients and discuss the contribution of functional neuroimaging and electrophysiological techniques to the bedside assessment of consciousness. These studies raise important issues not only from a clinical and ethical perspective (i.e. diagnosis, prognosis and management of DOC patients) but also from a neuroscientific standpoint, as they enrich our current understanding of the emergence and function of the conscious mind.
\end{abstract}

Keywords Brain injury $\bullet$ Coma $\bullet$ Consciousness $\bullet$ Electrophysiology $\bullet$ Functional neuroimaging $\bullet$ Locked-in syndrome - Minimally conscious state Prognosis $\bullet$ Treatment $\bullet$ Vegetative state

O. Gosseries • A. Vanhaudenhuyse $\bullet$ M.-A. Bruno $\bullet$

A. Demertzi • C. Schnakers • M.M. Boly • A. Maudoux

Coma Science Group, Neurology Department and Cyclotron Research Centre, University of Liège, Sart Tilman-B30, 4000 Liège, Belgium

G. Moonen

Department of Neurology, University of Liège, Liège, Belgium

S. Laureys (ه)

Coma Science Group, Neurology Department and Cyclotron Research Centre, University of Liège, Sart Tilman-B30, 4000 Liège, Belgium

and

Department of Neurology, University of Liège, Liège, Belgium

e-mail: steven.laureys@ulg.ac.be 


\subsection{Introduction}

In recent years, resuscitation techniques have led to a considerable increase in the number of patients who survive severe brain injuries. Some patients recover in the first days after the accident while others die quickly. Others, however, recover more slowly through different stages before fully or partially recovering consciousness. Patients in altered states of consciousness present major challenges concerning the diagnosis, prognosis and daily care. Indeed, detecting signs of consciousness is not always easy and, in some cases, they may remain unnoticed. Some of these signs are of prognostic importance. Prognosis, in turn, may influence therapeutic choices. The interdependency of these factors cannot be ignored: the announcement of a favorable outcome may imply the commitment of the medical team, while a bad prognosis may jeopardize the patient's potential recovery. End-of-life decisions, aggressive therapy with analgesic drugs and discussion about options of euthanasia often arise and, in many cases, lead to difficult debates among the medical staff, and sometimes more widely through the media and society.

\subsubsection{Two Components of Consciousness}

Clinically defined, consciousness encompasses two main components: arousal and awareness (Zeman 2001). At the bedside, arousal (also called vigilance or alertness) is observed by looking at the presence of eye opening. At a neuroanatomical level, the level of arousal (and in particular of sleep-wake cycles) is mainly supported by the brainstem (which is the region between the brain and the spinal cord), and the thalami (which are the nuclei in the center of the brain) (Schiff 2008; Lin 2000).

Awareness, the second component of consciousness, refers to conscious perception which includes cognition, experiences from the past and the present, and intentions. At a clinical level, awareness is mostly inferred by command following (e.g. "squeeze my hand", "close your eyes"). At a neuroanatomical level, awareness is underpinned by the cerebral cortex, which is a thin mantle of gray matter covering the surface of each cerebral hemisphere, and mainly through a wide frontoparietal network (see Sect. 3.2.1). Awareness can be further divided into awareness of the environment and awareness of self. Awareness of the environment can be defined as the conscious perception of one's environment through the sensory modalities (e.g. visual, auditory, somesthetic or olfactory perception) whereas awareness of self is a mental process that does not require the mediation of the senses and is not related to external stimuli for its presence (as shown by mind wandering, daydreaming, inner speech, mental imagery, etc.). Awareness of self also refers to the knowledge of our own social and cultural history as well as our family membership.

To be aware, we need to be awake but when awake, we are not necessarily aware. Consciousness depends on the interaction between the activity of the 
cerebral cortex, the brainstem and thalamus. When one of these systems is disrupted, consciousness gets impaired. Thus, consciousness is not an all-or-nothing phenomenon but lies on a continuum of states (Wade 1996). The various states of consciousness include wakefulness, deep sleep and paradoxical sleep (dreaming sleep, i.e. rapid eye movement sleep, REM sleep), anesthesia, coma, vegetative state and the minimally conscious state (Fig. 2.1). The boundaries between these different states are not always sharp but often are progressive transitions.

But how do these disorders of consciousness (DOC) occur? As illustrated in Fig. 2.2, after an acute brain injury that could be of traumatic (i.e. motor vehicle accident, falling, etc.) or non-traumatic (i.e. stroke, anoxia, etc.) etiology, patients may lose consciousness and fall into a coma. In most cases where the damage is severe, patients die within a few days. From the moment the patients open their eyes, they move out of a coma and, if still unresponsive, evolve into a vegetative state. Typically, the vegetative patient (VS) gradually recovers awareness and enters a minimally conscious state (MCS). This is often followed by a period of transient post-traumatic amnesia where the patient remains confused and amnesic. In most cases, the patient recovers within a few weeks, but in some cases, they may remain in a state of no awareness or minimal consciousness for several months or even years or decades. Another exceptional condition the locked-in syndrome (LIS), where the patient awake from the coma fully conscious but is unable to move or communicate, except by eye movements.

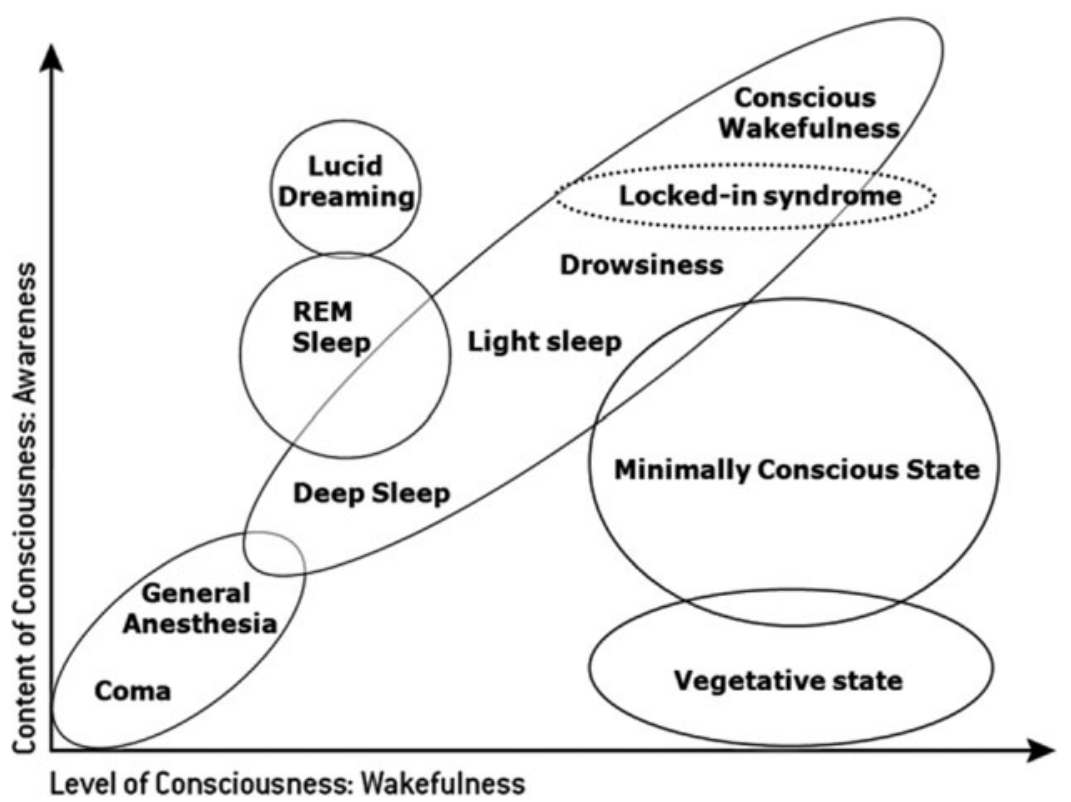

Fig. 2.1 Illustration of the two major components of consciousness: the level of consciousness (arousal or wakefulness) and the content of consciousness (awareness) in normal physiological states, where the level and the content of consciousness are generally positively correlated, and in pathological states or pharmacological coma (adapted from Laureys 2005) 


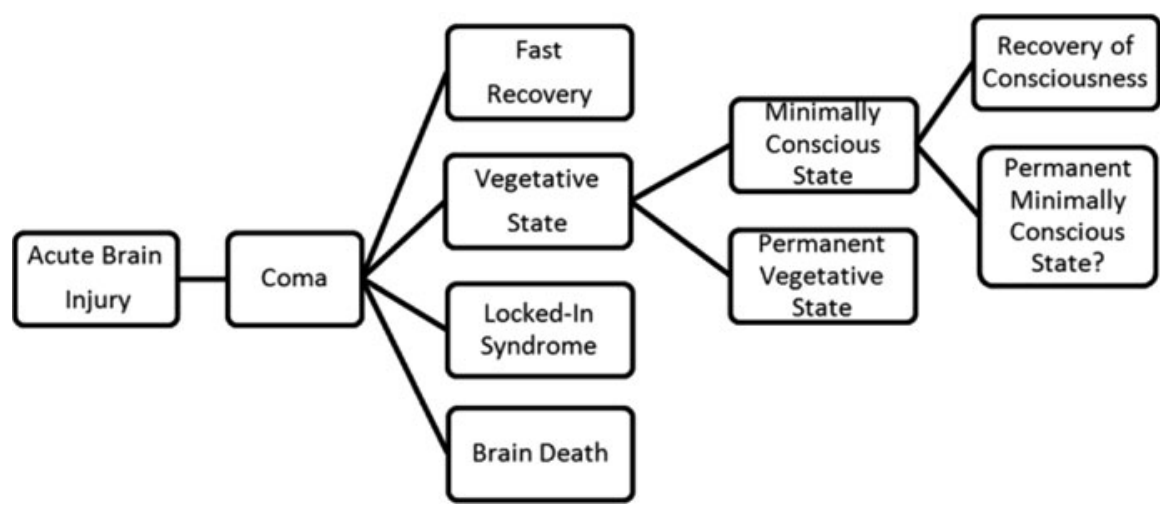

Fig. 2.2 Different conditions may follow acute brain injury. Classically, coma lasts for a couple of days, and once the patients open their eyes they evolve into a vegetative state. Then they may enter a minimally conscious state after showing some signs of consciousness, and eventually they recover full consciousness. In rare cases, a person may develop locked-in syndrome, a nearly complete paralysis of the body's voluntary motor responses

\subsubsection{Clinical Entities}

\subsubsection{Brain Death}

Brain death is characterized by the irreversible loss of all reflexes of the brainstem and the demonstration of continuing cessation of brain function and respiration in a persistently comatose patient (Laureys and Fins 2008). There should be an evident cause of coma, and confounding factors, such as hypothermia (low temperature), drugs intoxication, electrolyte, and endocrine disturbances should be excluded (Wijdicks 2001; Laureys 2005). Repeating the evaluation after $6 \mathrm{~h}$ is advised, but this time period is considered arbitrary (The Quality Standards Subcommittee of the American Academy of Neurology 1995). The absence of electrical brain activity by electroencephalogram (EEG) or the absence of cerebral blood flow may also serve as conformational tests (Laureys et al. 2004a).

\subsubsection{Coma}

Coma is a state of non-responsiveness in which the patients lie with eyes closed and cannot be awakened even when intensively stimulated (Plum and Posner 1983). Comatose patients are characterized by a lack of sleep-wake cycles (Teasdale and Jennett 1974) and they have neither verbal production nor response to command but can present reflexive responses to painful stimulation. In these patients, there is no awareness of self or of the environment. The autonomous functions such as breathing and thermoregulation are reduced and the patients require respiratory assistance. 
Global brain metabolism (i.e. energy use) is also diminished by $50-70 \%$ of normal (Laureys 2005). Coma results from a diffuse cortical or white matter damage, or from a brainstem lesion (Vanhaudenhuyse et al. 2009). Coma must last at least $1 \mathrm{~h}$ to be distinguished from syncope, concussion, or other states of transient unconsciousness. The prognosis is often made within 3 days; if the etiology is traumatic, half of the patients who have no chance to recover will die during this short period (Schnakers et al. 2004). Prolonged comas are rare but can last 2-5 weeks and then progress to brain death, a vegetative state, or more rarely a locked-in syndrome.

\subsubsection{Vegetative State}

The vegetative state (VS), or newly called unresponsive wakefulness syndrom (Laureys et al, 2010), is defined by eyes opening, either spontaneously or after stimulation. The sleep-wake cycles are characterized by alternating phases of eye opening. The autonomous functions are preserved and breathing occurs usually without assistance. Patients in a vegetative state exhibit no intelligible verbalization, no voluntary response and no signs of awareness of self or the environment (The Multi-Society Task Force on PVS 1994). The vegetative patient is awake but not aware, which shows that both components of consciousness can be completely separated. If patients are still in a vegetative state a month after brain injury, they are said to be in a persistent vegetative state. If patients with a non-traumatic etiology remain in this state for more than 3 months, or more than 1 year for patients with a traumatic etiology, they are said to be in a permanent vegetative state (American Congress of Rehabilitation Medicine 1995; Jennett and Plum 1972). The term "persistent" refers to a chronic phase and implies an unfavorable prognosis about the possibility of improvement. This terminology confuses the diagnosis and the prognosis, which induces a risk that certain therapies, such as a transfer to a rehabilitation center, are denied to patients diagnosed as in a persistent vegetative state. Similarly, the term permanent implies near zero probability of recovery and can therefore give rise to decisions about the cessation of medication and nutrition. It is preferable to avoid using these two terms (often both abbreviated as PVS) and rather mention the duration and cause of the vegetative state.

The brainstem functions of a vegetative patient are preserved, but cortical (including frontal and parietal cortex) and thalamic injuries are present. Brain metabolism is diminished by $40-50 \%$ of normal values (Laureys et al. 2000a). The vegetative patient is able to perform a variety of movements, such as grinding teeth, blinking and moving eyes, swallowing, chewing, yawning, crying, smiling, grunting or groaning, but these are always reflexive movements and unrelated to the context. Motor behavior is reduced to a few stereotyped or reflexive movements and is inadequate compared to the intensity of the stimulation. Typical vegetative patients do not track with their eyes a moving object or their image in a mirror. 


\subsubsection{Minimally Conscious State}

The minimally conscious state (MCS) (American Congress of Rehabilitation Medicine 1995; Giacino et al. 2002) is a more recently introduced entity and is characterized by primary and inconsistent signs of consciousness of self and the environment. Although patients are unable to communicate functionally, they can sometimes respond adequately to verbal commands and make understandable verbalizations. Emotional behaviors, such as smiles, laughter or tears may be observed. MCS patients may track a moving object, mirror or person (Giacino et al. 2002). Although these responses may be erratic, they must be reproducible in order to conclude that the action is intentional. These voluntary actions are quite distinct from reflexive movements if they are maintained for a sufficient period of time or repeated.

The overall cerebral metabolic activity is reduced by $20-40 \%$ (Laureys et al. 2004b). The autonomous functions are preserved and the thalamocortical and corticocortical connections are partly restored (Laureys et al. 2000b). The minimally conscious state may be transitory, chronic or permanent, such as the vegetative state.

\subsubsection{Emergence of the Minimally Conscious State}

Once patients are able to communicate in a functional way, they are said to have emerged from the minimally conscious state. They can therefore use multiple objects in an appropriate manner and their communication systems are adequate and consistent (Giacino et al. 2002). Because this entity is as recent as the minimally conscious state, validation and further research of other diagnostic criteria are still needed.

\subsubsection{Locked-In Syndrome}

Locked-in syndrome (LIS), also known as pseudocoma, is a complete paralysis of the body resulting from a lesion in the brainstem (American Congress of Rehabilitation Medicine 1995). Oral and gestural communications are impossible but patients are often able to blink and move the eyes. Despite the fact that the patients cannot move, their sensations are still intact and they are fully aware of their environment and themselves (Laureys et al. 2005a).

The only way for these patients to communicate with their environment is through eye movement and sometimes later also with the tip of a finger (Bauby 1997). Indeed, they generally recover some control of their fingers, toes or head. The LIS patient is able to answer questions by a simple code such as blinking once for "yes" and twice for "no", or looking up for "yes" and down for "no". Many means of communication have been developed to allow better communication, such as the use of the alphabet based on letter frequency used in English (i.e. E-T-A-O-I- 
N-S-R-H-L-D-C-U-M-F-P-G-W-Y-B-V-K-X-J-Q-Z) where the patient blinks when the interlocutor pronounces the desired letter. Here it is necessary to begin over again for each letter in order to form words and sentences. The use of a brain computer interface has also recently become an option and allows a LIS survivor to control his or her environment, use a word processor, operate a telephone or access the Internet and use email (Gosseries et al. 2009).

Nearly $90 \%$ of LIS cases are of vascular etiology but they can also be traumatic. Cognitive functions are fully preserved if the lesion is only restricted to the brainstem. If additional cortical lesions are present, the cognitive functions associated with these cortical areas may be affected (Schnakers et al. 2008). Contrary to what we might expect, the quality of life reported by chronic LIS patients is not that much lower than the general population (Bruno 2011) and the demand for euthanasia, albeit existing, is infrequent (Bruno et al. 2008).

\subsubsection{Prognosis}

The prognosis for survival and recovery from coma, VS, MCS or LIS is still difficult to establish at the individual level. Certain factors, however, increase the chances of recovery. The young age of the patient, a traumatic etiology and the short duration of the state are linked with a better outcome (The Multi-Society Task Force on PVS 1994). Additionally, patients who are in a MCS for 1 month after brain injury have better chances of recovery than patients who are in a VS 1-month post-injury. Life expectancy of most vegetative patients varies between 2 and 5 years, a few patients stay more than 10 years in this state whereas the average survival time for LIS patients is about 6 years. Of notice is the fact that exceptionally some patients can recover even many years after their trauma. Indeed, the American Terry Wallis, who suffered a car accident in 1984, recovered from the minimally conscious state in 2003, 19 years later, he started talking (Wijdicks 2006). Similarly, a Polish man suffered a brain trauma in 1988 and was able to communicate only 19 years later, in 2007.

Clinical and paraclinical assessments can also be used to establish a prognosis, such as the evaluation of the brainstem reflexes, the sensory evoked potential (SEP), the cognitive auditory evoked potential (such as P300 and mismatch negativity, $\mathrm{MMN}$ ), and the serum marker neuron-specific enolase (NSE). Some of these examinations are described in a later section.

\subsection{Clinical Examination}

In neurological rehabilitation, the distinction between a vegetative and a minimally conscious state is of great importance, because of the implications in terms of prognosis and treatment decisions, but also at the medico-legal and ethical level. 
The main method - known as the gold standard - for detecting signs of consciousness is behavioral observation (Schnakers et al. 2004). The assessment of consciousness in DOC patients is essential from admission throughout hospital discharge in order to obtain information on their cognitive progress and to define appropriate care. Clinical evaluations are therefore used to assess the awareness of self and the environment of the patient. However, no technique is yet available to measure consciousness directly. We can identify its presence but it is much more difficult to prove its absence.

\subsubsection{Misdiagnosis in Disorders of Consciousness}

Although behavioral assessments are essential in evaluating consciousness, they are sometimes difficult to complete. A patient in a minimally conscious state can be diagnosed as being in a vegetative state, just as a LIS patient can be easily confused with a vegetative state. Indeed, voluntary movements may be wrongly interpreted as reflex movements and motor responses may be very limited due to a paralysis of all limbs (quadriplegia). Motor responses can also be quickly exhaustible and therefore not reproducible (Schnakers et al. 2004). The level of arousal can also fluctuate and patients may become drowsy or even fall asleep while evaluating them. All these boundaries lead to diagnostic errors. Studies have shown that $20-40 \%$ of patients diagnosed as vegetative showed signs of consciousness when assessed with sensitive and reliable standardized tools (consciousness scales) (Schnakers et al. 2006, Andrews et al. 1996, Childs and Mercer 1996, Schnakers et al. 2009).

The differential diagnosis requires repeated behavioral assessments by trained medical staff. The risk of misdiagnosis increases if the staff is unfamiliar with the clinical signs of these states. The controversy of some behaviors as reflecting consciousness or not just comes to add further perplexity. For example, blinking to visual threat should not be considered as a sign of consciousness (Vanhaudenhuyse et al. 2008a) whereas visual pursuit clearly should (Giacino et al. 2002). Moreover, the latter can be tested with different tools but it has been revealed that the best means for assessing visual pursuit is the use of a mirror which (by presenting the patient's own face) has the important ability to grab attention (Vanhaudenhuyse et al. 2008b). To avoid events of misdiagnosis, it is necessary that well-experienced personnel use standardized assessments, such as scales and individual testing, in order to objectify the clinical observations.

\subsubsection{Consciousness Scales}

Many standardized behavioral scales are used in the assessment of consciousness of brain injured patients: the Glasgow Coma Scale (GCS) (Teasdale and Jennett 
1974), the Glasgow Liège Scale (Born 1988a), the Coma Recovery Scale-Revised (Giacino et al. 2004), the Full Outline of Unresponsiveness (Wijdicks et al. 2005), the Wessex Head Injury Matrix (Shiel et al. 2000), the Coma-Near Coma scale (Rappaport 2000), the Western Neuro-Sensory Stimulation Profile (Ansell and Keenan 1989), and the Sensory Modality Assessment and Rehabilitation Technique (Gill-Thwaites 1997) are among the most used. Some scales are an aid for diagnoses in the early hours of patients' admission in the intensive care unit (e.g. the GCS and FOUR) while others are rather used throughout the recovery (e.g. CRS-R). Here we review the scales that are used most frequently in clinical practice.

\subsubsection{Glasgow Coma Scale and Glasgow Liège Scale}

The Glasgow Coma Scale (GCS) is the scale of reference used internationally, due to its short and simple administration. It is mainly used in intensive care settings. The GCS measures eye, verbal and motor behaviors. However, the verbal response is impossible to assess in the case of intubation or tracheotomy (patients with artificial respiratory help making speech impossible). Additionally, there may be some concern as to what extent eye opening is sufficient for assessing brainstem function (Laureys et al. 2002a). The total score varies between 3 and 15. In acute stages, brain damage is described as serious if the score is less than or equal to 8 and moderate if the score is between 9 and 12 (Deuschl and Eisen 1999). The Glasgow Liège Scale (GLS) is an extended version of the GCS which includes the standardized evaluation of brainstem reflexes (Born 1988b).

\subsubsection{Full Outline of Unresponsiveness}

The Full Outline of Unresponsiveness (FOUR) is a more recent scale that has been proposed to replace the GCS as it detects more subtle neurological changes (Wijdicks et al. 2005). The scale is named after the number of subscales (eye, motor, brainstem reflexes and respiration) as well as after the maximum score that each subscale can take (four). The assessment takes only a few minutes to administer. It does not include a verbal response, and can therefore be used to assess artificially ventilated or intubated patients. The FOUR is particularly suitable for diagnosing vegetative state, locked-in syndrome and brain death. It also allows to differentiate between VS and MCS patients as it assesses visual pursuit, one of the first signs of recovery of consciousness (Giacino et al. 2002).

\subsubsection{Coma Recovery Scale-Revised}

The Coma Recovery Scale-Revised (CRS-R) also is a recent clinical tool that has been specifically developed to disentangle VS from MCS patients, but also MCS 
patients from patients who recovered their ability to communicate functionally (Giacino et al. 2004). Indeed, it is the only scale to explicitly incorporate the diagnostic criteria of vegetative and minimally conscious state. It consists of six subscales: auditory, visual, motor and oromotor/verbal functions as well as communication and arousal. The 23 items are ordered according to their degree of complexity; the lowest item on each subscale represents reflexive activity while the highest item represents behaviors that are cognitively mediated. Scoring is based on the presence or absence of operationally defined behavioral responses to specific sensory stimuli (e.g. if the item of visual pursuit is present, the patient's state is diagnosed as minimally conscious). The brainstem reflexes are also measured but not scored. The assessment takes between 10 and $60 \mathrm{~min}$, depending on the patient's responsiveness. In many research centers, the CRS-R is regarded as the gold standard for the behavioral assessment of severely brain injured patients. The scale has been translated and validated in several languages (Schnakers et al 2008) and is freely available (see http://www.comascience.org).

\subsubsection{Wessex Head Injury Matrix}

The objective of this scale is to create a transition between the assessment of coma in acute stages and the realization of neuropsychological tests that are applied much later. The evaluation is based on observations for presence or absence of behaviors. The WHIM has been designed to pick up minute indices demonstrating recovery and it covers a wide range of daily life functions. It assesses motor and cognitive skills, social interactions, the level of wakefulness and the auditivo-verbal, visualmotor and tactile modalities (Majerus and Van der Linden 2000). Compared to the CRS-R, this 62 item matrix assesses the patient without giving any diagnosis, since it does not incorporate the criteria of VS and MCS. It is more useful in assessing MCS patients who show minimal improvement, and in setting goals for rehabilitation from the outset of coma.

\subsubsection{Individual Bedside Assessment}

Another way to assess severely brain injured patients, which is complementary to the standardized scales, is a quantitative assessment based on the principles of single-subject experimental design. This method identifies whether a specific behavior of interest can be performed in response to command and whether the reliability of this behavior can change over time either spontaneously or in response to treatment (Whyte et al. 1999). The presence of command-following is crucial evidence of consciousness and facilitates differentiation between MCS and VS patients. The ability to follow a command is also important in the rehabilitation process because it means the patient can participate in therapies. 
It can also be the starting point of communication. Indeed, specific movements can be used as a means of communication such as "make a thumbs up" for yes and "shake your head" for no.

Quantitative assessment can also lead to conclusions about a patient's visual function that are not readily apparent by clinical observation (Whyte and DiPasquale 1995). Attention deficits, blindness, gaze preference, monocular pathology and impairment in one or both visual fields can be observed objectively through this method by showing the patient a blank card or a photograph, either individually or at the same time, in both visual fields. Systematic visual orienting that involves visual discrimination is evidence of cortical function (i.e. if the patient looks at a picture more often than a blank card). The awareness of these deficits may help to avoid confounding the assessment of a patient's cognitive functions and can also help to adapt the therapy. For example, if a patient presents a left-sided neglect, the therapist should be positioned primarily on the right side to optimize patient's responsiveness.

\subsection{Complementary Examination}

Brain imaging and electrophysiology techniques are objective ways to investigate residual brain functions in disorders of consciousness. They may show the extent of brain damage for diagnostic, prognostic and therapeutic purposes and can also be used in experimental research. The imaging techniques can therefore lead to a better understanding of the behavioral clinical observations. To simplify, we present two main types of methods which are used for cognitive neuroimaging studies: metabolic or hemodynamic measurements (e.g. positron emission tomography, PET; functional magnetic resonance imaging, fMRI) and electrical measurements (e.g. electroencephalography, EEG; event related potentials, ERP). The PET technique can measure changes in the brain's metabolism using a radioactive tracer (labeled glucose) that is injected into the blood and is accumulated by active areas of the brain (using energy from the glucose). The fMRI indirectly measures regional increases in blood flow by analyzing the magnetic resonance properties of hemoglobin, which varies depending on the blood's oxygenation (energy use). These functional neuroimaging techniques should be distinguished from structural imaging such as X-ray CT or conventional MRI (offering imaging of the brain without telling anything about their functioning). Electrical measurements collect signals that are related to the intracellular electric current of the brain. PET and fMRI techniques have good spatial resolution but their temporal resolution is poor, whereas EEG methods have excellent temporal resolution but spatial resolution is relatively low and signals from deeper areas are difficult to identify (Laureys and Boly 2008). 


\subsubsection{Electroencephalography}

Electroencephalography (EEG) records continuously and non-invasively the spontaneous electrical brain activity through electrodes placed on the scalp. The EEG well identifies the level of vigilance (Fang et al. 2005) and detects functional cerebral anomalies such as seizures. It can also be used to confirm the clinical diagnosis of brain death (Guérit et al. 2002). The utility of the EEG has been demonstrated to predict poor recovery of patients with brain anoxic and traumatic injury (Zandbergen et al. 1998). However, most of the EEG patterns are not specific (Young 2000) and do not allow reliable differentiation between conscious and unconscious brain processing. The interpretation of raw EEG signals also requires considerable expertise and training. More automated measures deriving from the EEG are therefore welcome, such as the EEG bispectral index measurements.

\subsubsection{Bispectral Index}

The bispectral index (BIS) measures the depth of sedation in anesthesia (Struys et al. 1998) and allows distinction between the different phases of normal sleep (Nieuwenhuijs et al. 2002). BIS values range between 0 and 100: when the subject is awake the values approach 100, whereas when the subject is under general anesthesia, values are around 40-50. BIS values also gradually increase when patients move out from coma to recovery (Schnakers et al. 2008a). However, BIS is a nonspecific measure of consciousness and does not systematically differentiate MCS from VS patients, even if it seems to show prognostic utility (Schnakers et al. 2005b).

\subsubsection{Event-Related Potentials}

The event-related potential (ERP) technique objectively examines sensory and cognitive functions at the patient's bedside by averaging the EEG activity according to the onset of a repeated stimulus (e.g. noise or visual flash). ERPs reveal the time course of information processing from low-level peripheral receptive structures to high-order associative cortices (Vanhaudenhuyse et al. 2008c). Short-latency ERPs, or exogenous ERP components (ranging from 0 to $100 \mathrm{~ms}$ ), correspond to the passive (automatic) reception of external stimuli whereas cognitive ERPs, or endogenous ERP components (obtained after $100 \mathrm{~ms}$ ), often reflect cognitive neuronal activity. The ERPs provide neurological markers, where the absence of early ERPs is a good predictor of a bad outcome (i.e. absence of primary cortical responses on somatosensory ERPs) and the presence of cognitive ERPs a good predictors of a favorable outcome (i.e. P300 and Mismatch Negativity responses) (Daltrozzo et al. 2007). 


\section{Short-Latency ERPs}

Sensory evoked potentials (SEPs) are short-latency ERPs that are routinely used in intensive care. They measure the connection from the body to the brain (called the ascending pathways, which involve the spinal cord, the brainstem, and the primary sensory cortex). Practically, electrical stimulations are elicited from the wrist and the responses are recorded at the level of the nerves, spinal cord, brainstem and cortical levels. Bilateral absence of the cortical response (N20) among patients in coma, especially in anoxic patients who had a lack of oxygen in the brain, after for example cardiac arrest, is strongly associated with poor outcome, but preserved SEPs do not necessarily herald recovery (Cant et al. 1986; Laureys et al. 2005b).

\section{Long-Latency Cognitive ERPs}

Mismatch negativity (MMN) is a cognitive ERPs response elicited after approximately 100-200 ms by any change in a sequence of monotonous auditory stimuli in inattentive subjects (Naatanen and Alho 1997). It assesses the residual brain activity and more specifically the integrity of echoic memory, a memory that permits a sound to be remembered in the 2 or $3 \mathrm{~s}$ after it is heard. The presence of MMN has prognostic value in predicting recovery after coma (Kane et al. 1996; Fischer et al. 2004; Naccache et al. 2005; Qin et al. 2008).

The auditory evoked potentials P300 response is another ERP wave which is also elicited (around $300 \mathrm{~ms}$ after the stimulus) when subjects detect a rare and unpredictable target stimulus in a regular train of standard stimuli (Sutton et al. 1965). It assesses the integrity of acoustic and semantic discrimination. The presence of P300 and MMN is associated with a favorable clinical outcome but their absence does not necessarily imply a poor prognosis as these components can also be absent in some healthy controls, as well as in a significant number of patients who later recover consciousness (van der Stelt and van Boxtel 2008).

The P300 wave can also be observed in response to the patient's own name in VS and MCS patients, when they hear their own name in a sequence of unfamiliar names in a passive condition (Perrin et al. 2006). When asking patients to perform a cognitive task such as counting the number of times they hear their own name, the P300 to the own name stimuli increases (Schnakers et al. 2008b). This permits a demonstration that patients with apparently no behavioral sign of consciousness may be conscious (i.e. show command following) (Schnakers et al. 2009, p. 4588). The P300 ERP technique is also being used to permit EEG-based communication (i.e. in Brain Computer Interface technology) (Sellers et al. 2006), which could allow LIS patients to communicate through their electrical brain activity without moving a single muscle. 


\subsubsection{Functional Neuroimaging}

\subsubsection{Resting State}

PET studies have shown that global cerebral metabolism during deep sleep and general anesthesia is diminished by about half of normal values (Maquet et al. 1997; Alkire et al. 1999). The brain metabolism of VS patients is also reduced by $50-60 \%$ (Laureys et al. 1999; Levy et al. 1987). However, when the patient has clinically recovered, brain metabolism does not always return back to normal (Fig. 2.3) (Laureys et al. 2000c).

Some brain regions appear to be more important than others for the emergence of consciousness. At rest, patients in a vegetative state show systematic impairment of metabolism in the frontoparietal network that includes polymodal associative cortices (bilateral prefrontal regions, Broca's area, parietotemporal and posterior parietal areas, and precuneus) (Laureys et al. 2006a).

These regions are essential in various functions that are necessary for consciousness, such as attention, memory, and language (Baars et al. 2003). Conscious perception is also linked to the functional connectivity between this frontoparietal network and deeper centers of the brain, such as the thalamus (Fig. 2.4). In vegetative patients, the long-distance connections between different cortical areas as well as between the cortex and the thalamus seem disconnected. The recovery of patients in a vegetative state is linked to the restoration of this frontoparietal network and its connections (Laureys et al. 2000b).

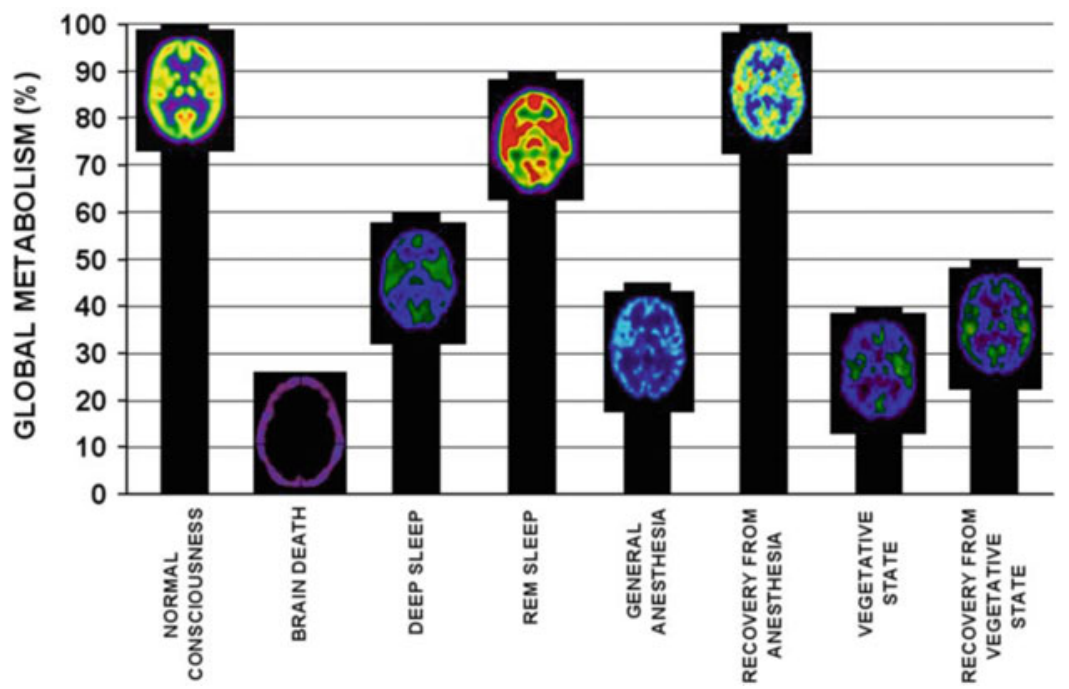

Fig. 2.3 Global cerebral metabolism in various states (adapted from Laureys et al. 2004a) 


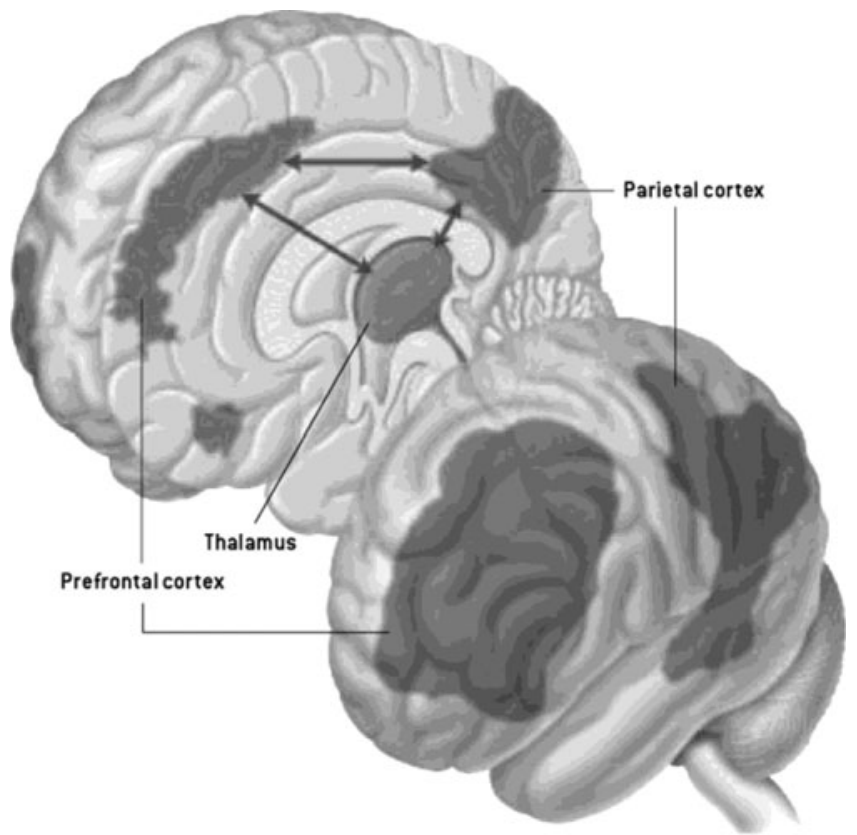

Fig. 2.4 Brain regions encompassing prefrontal and parietal multi-modal associative areas (known as the frontoparietal network) are crucial for consciousness. Conscious perception is also linked to the functional connectivity between this frontoparietal network and deeper centers of the brain such as the thalamus. The vegetative state is characterized by a metabolic dysfunction of this widespread cortical network shown in dark grey (adapted from Laureys 2007)

\subsubsection{External Stimulation}

Despite a massively reduced resting metabolism, primary cortices still seem to be activated during external stimulation in vegetative patients, whereas hierarchically higher-order multimodal association areas are not. When painful stimuli are administered to vegetative patients, only the brainstem, the thalamus and the primary somatosensory cortex are activated, and the latter is isolated and disconnected from the other brain areas, in particular the frontoparietal network (Boly et al. 2005; Laureys et al. 2002b). These findings support the idea that patients in a vegetative state do not consciously perceive pain as do healthy people. In contrast to VS, MCS patients, similar to control subjects, show activation of the complete pain matrix (thalamus, primary and secondary somatosensory, frontoparietal, and anterior cingulate cortices) and show a preserved functional connectivity between these areas (Boly et al. 2008). These results provide evidence for a preserved conscious pain perception capacity in MCS patients, strongly suggesting that these patients should receive pain treatment when needed.

Similarly, in response to auditory stimuli, brain activity in vegetative patients is limited to the primary auditory cortex while polymodal areas of higher order do 
not become active and remain functionally disconnected (Boly et al. 2004; Laureys et al. 2000d). This primary brain activation does not seem enough to lead to conscious perception and memory formation. In contrast, patients in a minimally conscious state activate higher-order cortical areas. More specifically, a recent study showed a selective impairment in backward connectivity from frontal to temporal cortices in vegetative patients whereas minimally conscious patients present a similar pattern to healthy subjects with preserved feedforward and topdown processes (Boly et al. 2011) Auditory stimuli with emotional content, such as baby cries or the patient's own name, induce even more extensive brain activation than sounds without meaning (Fig. 2.5) (Laureys et al. 2004b; Boly et al. 2005). This implies that content is important when talking to patients in a minimally conscious state.

Similarly, in response to presentation of the patient's own name uttered by a familiar voice, the primary auditory cortices of five VS patients were activated, but none of these patients recovered. In contrast, two other VS patients showed atypical activation of both primary cortex and higher-level associative cortex, and they improved clinically to MCS 3 months after their scan (Di et al. 2007). Another fMRI study showed that MCS patients demonstrated similar responses to healthy volunteers when listening to passive language with personalized narratives. However, when the narratives were presented as a time-reversed signal (without linguistic content) MCS patients demonstrated markedly reduced responses, suggesting again reduced engagement for linguistically meaningless stimuli (Schiff et al. 2005).

Another fMRI study based on mental imagery tasks has been proposed to identify signs of consciousness in non-communicative patients (Boly et al. 2007). Despite the clinical diagnosis of vegetative state, a 23-year-old girl who suffered a traumatic brain injury 5 months earlier showed signs of consciousness only detectable on fMRI (Owen et al. 2006). She was asked to imagine herself playing tennis and walking

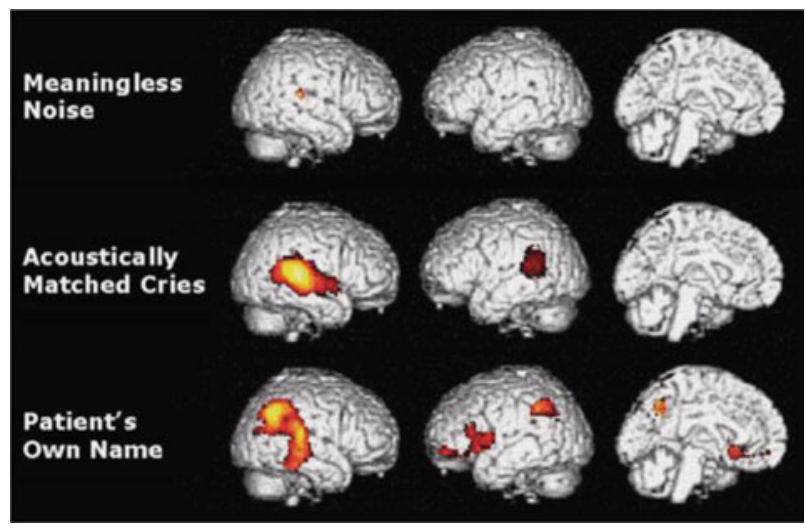

Fig. 2.5 Brain activations during presentation of noise, baby cries, and the patient's own name. Stimuli with emotional valence (baby's cries and names) induce a much more widespread activation than does meaningless noise in the minimally conscious state (taken from Laureys et al. 2004) 


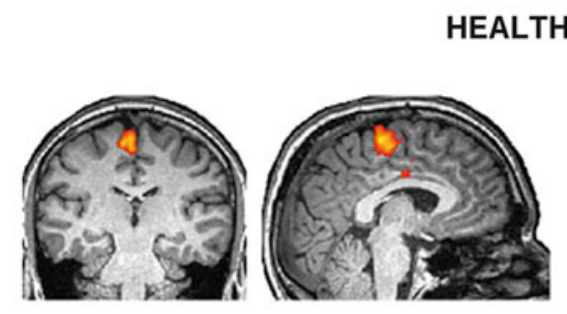

Answers «YES »

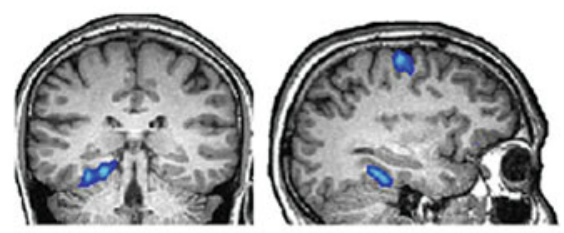

Answers « NO »

« VEGETATIVE STATE »
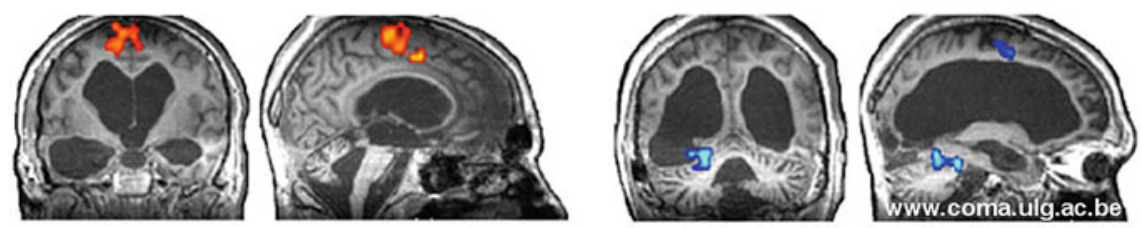

Fig. 2.6 A patient (top two images) who was clinically diagnosed as vegetative showed similar brain activity to a healthy subject (bottom two images) when asked to imaging playing tennis (left) or visiting her own house (right). A few months after the study, the patient recovered consciousness (taken from Owen et al. 2006)

through her house. The results showed brain activation similar to that of the control subjects for both tasks (Fig. 2.6). This study shows clear evidence of awareness and command-following in the absence of voluntary motor responsiveness. The patient evolved into MCS several weeks later and she was probably in a stage of transition from vegetative to recovery of consciousness at the time of assessment. Finally, another study recently showed that it has been possible for a vegetative patient to communicate through the fMRI. He could answer questions by imaging playing tennis when he wanted to say "yes" and imaging moving into his house when he wanted to respond "no" (Monti and Vanhaudenhuyse et al, 2010).

\subsection{Treatment}

There is currently no effective standardized treatment for DOC patients. Most of the studies have been conducted under suboptimal settings with methodological and conceptual problems, with the consequence that no strong evidence-based recommendations can be made. However, uncontrolled studies indicate that some rehabilitative procedures can promote the recovery of consciousness, especially in MCS patients. These interventions can be divided into pharmacological and nonpharmacological treatments. 


\subsubsection{Pharmacologic Treatment}

The effect of pharmacological agents on recovery in chronic disorders of consciousness still remains unsatisfactory (Laureys et al. 2006b; Demertzi et al. 2008). Several therapeutic trials have been conducted with post-comatose patients and have led to a marked improvement in their level of consciousness. Zolpidem is a drug originally used in the treatment of insomnia that has occasionally the opposite effect in brain damaged patients. A recent study showed that on 15 patients, only one demonstrated a clinically significant response after the administration of the medication, suggesting a response rate to zolpidem around 7\% (Whyte et al. 2009). The effect of Zolpidem was first reported after its use in a 23 -year-old man who had been in a vegetative state for more than 3 years following a motor vehicle accident. The patient regained consciousness 15 min after being administered the drug and was able to greet his mother for the first time in 3 years. He was able to sigh, to talk and to communicate with his family (Clauss et al. 2000). But after the effects of the drug wore off, he relapsed, returning to his previous state. Zolpidem has therefore only a temporary effect and lasts for a maximum of a few hours. Temporary improvements have since been observed in stroke and near drowning patients (Clauss and Nel 2004), anoxic brain injury (Cohen and Duong 2008), vegetative (Clauss and Nel 2006) and minimally conscious states (BrefelCourbon et al. 2007; Shames and Ring 2008). The results varied from a regain of consciousness to an enhancement of motor, verbal and cognitive functions, as well as gestural interaction and arousal. The exact underlying mechanism of the effect of Zolpidem remains unclear (Clauss et al. 2004).

Amantadine is another drug that produces similar effects on VS and MCS patients but its effects last longer (Whyte et al. 2005; Zafonte et al. 2000). It is a dopaminergic agent (also acting on NMDA receptors) initially used against the flu and in the treatment of Parkinson's disease. A recent study involving a chronic anoxic MCS patient showed cognitive improvement after 3 weeks of Amantadine treatment, such as reproducible movement to command (i.e. touching a ball with the feet) and consistent automatic motor responses (i.e. mouth opening when a spoon is approaching). These improvements were associated with an increase in frontoparietal cortical metabolism which is considered important in consciousness (Schnakers et al. 2008c).

Other pharmacological agents that have been reported as inducing functional recovery are Levodopa, Bromocriptine (Passler and Riggs 2001) Apomorphine (Fridman et al. 2010), and Baclofen (Taira and Hori 2007). Large scale studies on the efficacy of these drugs are still warranted. More specifically, cohort placebocontrolled randomized trials and blinded within-subject crossover designs are needed before reaching any definite conclusions concerning the efficacy of the pharmacological treatment of DOCs. 


\subsubsection{Non-pharmacological Treatment}

Deep brain stimulation (DBS) has been proposed as a strategy to improve the functional level of chronic non-communicative patients. This technique consists of implanting an electrode in the brain (more specifically in this case in the thalamus) in order to reactivate a widespread cerebral connectivity mechanism that supports communication and goal-directed behavior. Bilateral DBS of the central thalamus has been performed in a 38-year-old patient who remained in a MCS for 6 years following a traumatic brain injury (Schiff et al. 2007). The electrodes were placed in the intralaminar thalamic nuclei. It has been shown that these thalamic nuclei restore cortical connectivity in the recovery of consciousness after VS (Laureys 2000b, p. 2913). Before applying DBS, the MCS patient failed to recover consistent command following and remained in a non-verbal state without any sign of functional communication. His fMRI, however, showed the preservation of a bihemispheric large-scale cerebral language network, which demonstrates that further recovery was possible (Schiff et al. 2005). During periods in which DBS was on (as compared to periods in which it was off), levels of arousal, motor control and interactive behavior increased considerably. The patient was able to respond consistently to commands and produced intelligible verbalization. The DBS technique can therefore promote a significant functional recovery from severe traumatic brain injury. Nevertheless, replicas of these findings are still needed to validate the technique.

Other non-pharmacologic and non-invasive interventions are the multimodal sensory stimulation techniques which provide frequent sensory input to all five senses in the hope that it will enhance synaptic reinnervation and accelerate neurological recovery (Demertzi et al. 2008; Tolle and Reimer 2003). Sensory stimulation is also intended to prevent sensory deprivation and facilitates coherence between the brain and the body. Sensory regulation is a variant of sensory stimulation that facilitates information processing by adjusting the time exposure and the complexity of the stimuli according to the level of the patient's capacity (Wood et al. 1992). The stimulation sessions are alternated with resting periods in order to increase the ability of the patient to respond during stimulation sessions. Finally, physical and occupational therapy are usually used in rehabilitation centers to prevent complications and enhance recovery. There is uncontrolled evidence that early and increased intervention leads to better outcomes (Oh and Seo 2003; Shiel et al. 2001). The beneficial effects of all these techniques are still debated and are not yet based on evidence.

\subsection{Ethical Issues}

DOC patients, especially patients in vegetative state, present important ethical and moral issues (Demertzi et al in press). In many countries, it is legally permissible to withdraw life-sustaining treatment once the patient is diagnosed as being in a 
permanent VS (i.e. with no hope of recovery), if such withdrawal seems likely to be what the patient would have wanted (Jennett 2005). It is therefore recommended to make an advance directive concerning personal wishes in the event of vegetative survival that could legitimately be used by the doctor to withdraw or to sustain the treatment (Demertzi et al 2011).

Three cases have generated considerable debate, positioning pro-life advocates against those defending the right to die with dignity. American Karen Ann Quinlan suffered a cardio-pulmonary arrest in 1975 and became vegetative. Her parents signed the authorization to disconnect the respirator, but the hospital authorities refused because the parents did not have legal custody. A judicial process began and a year later the court gave legal custody to the parents. Karen was disconnected but, against all odds, she continued breathing by herself. She survived in this vegetative state for 9 years until her death in 1985 (Dundon 1978). The case of the American Terri Schiavo is similar but here the parents wished to keep her alive against the wishes of her husband and despite the advice of doctors. After suffering a respiratory insufficiency in 1990, Terri was considered as being in a permanent vegetative state but this diagnosis was criticized by the parents still hoping for a recovery (Cochrane 2006). The Supreme Court of the United States finally rejected the request of her parents to keep her alive and she died in 2005, 13 days after the disconnection of her feeding tube. The most recent case involved the Italian Eluana Englaro, who was left in a vegetative state after a motor vehicle accident in 1992. Her father requested shortly after the accident to have her feeding tube removed but the authorities refused his request. He received the authorization only 17 years later. She finally died in February 2009.

It is also ethically controversial for some whether or not non-communicative patients can be included in clinical trials, as they are unable to provide their agreement. Informed consent is therefore requested from the patient's legal surrogate. The medical community is redefining an ethical framework in order to balance protection for post-comatose patients against the facilitation of research and medical progress (Fins 2003; Fins et al. 2008).

\subsection{Conclusion}

Defining consciousness as having two components (arousal and awareness) helps us also define the corresponding clinical entities. Coma means lack of consciousness (unarousable unawareness), whereas in the vegetative state arousal is preserved but awareness is absent (arousable unawareness). In the minimally conscious state, arousal is also present but with fluctuating and minimal signs of awareness. Lockedin syndrome has to be differentiated from those disorders of consciousness, as consciousness is intact but voluntary motor control is completely impaired (except for eye movements). In clinical practice, although the Glasgow Coma Scale remains the gold standard for the assessment of comatose patients, the Coma Recovery Scale-Revised is more appropriate in differentiating between 
vegetative and minimally conscious or locked-in patients. Misdiagnosis is still too frequent in clinical practice despite the introduction of diagnostic criteria. Conscious patients can indeed be diagnosed as vegetative if they have unnoticed paralysis or if voluntary movements are erroneously interpreted as reflexes. Family members of LIS patients are often the first to realize that the patient is conscious (Laureys et al. 2003; Leon-Carrion et al. 2002). Standardized behavioral scales and quantitative individual assessments should therefore be employed repetitively in the clinical routine by trained medical staff, in order to minimize the risk of erroneous diagnosis.

Technological advances in neuroimaging allow us to increase our understanding of the human brain and this knowledge can be exploited in order to develop new diagnostic, prognostic and therapeutic approaches (Laureys and Boly 2008). Studies have shown that the vegetative state is characterized by a functional cortical disconnection syndrome. Only primary cortex can be activated and is disconnected from the higher-order frontoparietal network. In the minimally conscious state, however, the latter areas can be activated especially by emotionally meaningful or noxious stimuli. It has also been shown that neuronal plasticity (e.g. axonal regrowth) may exist, sometimes many months to years after the brain trauma, and this could promote the recovery of consciousness in MCS patients (Schiff et al. 2005; Voss et al. 2006).

DOC patients have rather limited therapeutic options. Basic therapies include life-sustaining therapy (i.e. artificial nutrition and hydration) as well as physical and occupational therapies that are used to prevent complications and enhance recovery (the latter awaits controlled trials). Pharmacologic trials (with Amantadine and Zolpidem) have shown behavioral improvements in some uncontrolled case reports or series of brain injured patients. Deep brain stimulation and multisensory stimulations also showed some positive results but are clearly still in the research domain. Nowadays, therapeutic management lacks large-scale double-blind randomized placebo controlled trials. Much more research and methodical validation are required before accepting or rejecting specific treatments.

Advanced communication techniques based on mental imagery and on cognitive event-related potentials using active paradigms are also currently being investigated. Indeed, brain computer interface (BCI) devices allow brain signals to control external devices without requiring any muscular activity. For example, mental imagery and measurement of the salivary $\mathrm{pH}$ can permit a LIS patient to communicate: to say "yes", the patient had to imagine a lemon, which increases salivary $\mathrm{pH}$, whereas to say "no", the patient had to imagine milk, which decreases pH (Wilhelm et al. 2006; Vanhaudenhuyse et al. 2007). Also, it is expected that BCI techniques will be used clinically as a diagnostic tool for differentiating between conscious and unconscious patients (Kubler and Kotchoubey 2007, Sorger 2009), as we have previously seen with the fMRI tennis and spatial mental imagery paradigms.

Neuroimaging studies are moving from the research field to the clinical application of these techniques currently being validated by multi-centric cohort studies. These paraclinical examinations are providing additional information, unavailable 
through bedside clinical assessments, which is being used to better understand the patient's diagnosis and prognosis. It can be predicted that in the near future, multimodal approaches combining bedside examination, electrophysiology and functional imaging techniques will be routinely employed to assess and treat these challenging patients with disorders of consciousness.

Acknowledgments This research was funded by the Belgian National Funds for Scientific Research (FNRS), the European Commission (CATIA, DISCOS, MINDBRIDGE, DECODER), the James McDonnell Foundation, the Mind Science Foundation, the French Speaking Community Concerted Research Action, the Foundation Médicale Reine Elisabeth and the University and University Hospital of Liège.

\section{References}

Alkire MT, Pomfrett CJ, Haier RJ et al (1999) Functional brain imaging during anesthesia in humans: effects of halothane on global and regional cerebral glucose metabolism. Anesthesiology 90(3):701-709

American Congress of Rehabilitation Medicine (1995) Recommendations for use of uniform nomenclature pertinent to patients with severe alterations of consciousness. Arch Phys Med Rehabil 76:205-209

Andrews K, Murphy L, Munday R et al (1996) Misdiagnosis of the vegetative state: retrospective study in a rehabilitation unit. BMJ 313(7048):13-16

Ansell BJ, Keenan JE (1989) The western neuro sensory stimulation profile: a tool for assessing slow-to-recover head-injured patients. Arch Phys Med Rehabil 70(2):104-108

Baars B, Ramsoy T, Laureys S (2003) Brain, conscious experience and the observing self. Trends Neurosci 26:671-675

Bauby J-D (1997) The diving bell and the butterfly (original title: Le scaphandre et le papillon).

Boly M, Faymonville ME, Peigneux P et al (2004) Auditory processing in severely brain injured patients: differences between the minimally conscious state and the persistent vegetative state. Arch Neurol 61(2):233-238

Boly M, Faymonville ME, Peigneux P et al (2005) Cerebral processing of auditory and noxious stimuli in severely brain injured patients: differences between VS and MCS. Neuropsychol Rehabil 15(3-4):283-289

Boly M, Coleman MR, Davis MH et al (2007) When thoughts become action: an fMRI paradigm to study volitional brain activity in non-communicative brain injured patients. Neuroimage 36 (3):979-992

Boly M, Faymonville ME, Schnakers C et al (2008) Perception of pain in the minimally conscious state with PET activation: an observational study. Lancet Neurol 7(11):1013-1020

Boly M, Garrido MI, Gosseries O, Bruno MA, Boveroux P, Schnakers C, Massimini M, Litvak V, Laureys S, Friston K. Preserved feedforward but impaired top-down processes in the vegetative state. Science. 2011 May 13;332(6031):858-62

Born JD (1988a) The Glasgow-Liège Scale. Prognostic value and evaluation of motor response and brain stem reflexes after severe head injury. Acta Neurochir 95:49-52

Born JD (1988b) The Glasgow-Liege Scale. Prognostic value and evolution of motor response and brain stem reflexes after severe head injury. Acta Neurochir Wien 91(1-2):1-11

Brefel-Courbon C, Payoux P, Ory F et al (2007) Clinical and imaging evidence of zolpidem effect in hypoxic encephalopathy. Ann Neurol 62(1):102-105

Bruno M, Bernheim J, Schnakers C et al (2008) Locked-in: don't judge a book by its cover. J Neurol Neurosurg Psychiatry 79:2 
Bruno MA, Bernheim J, Ledoux D, Pellas F, Demertzi A, Laureys S (2011) A survey on selfassessed wellbeing in a cohort of chronic locked-in syndrome patients: happy majority, miserable minorityBritish Medical Journal - Open

Cant BR, Hume AL, Judson JA et al (1986) The assessment of severe head injury by short-latency somatosensory and brain-stem auditory evoked potentials. Electroencephalogr Clin Neurophysiol 65(3):188-195

Childs NL, Mercer WN (1996) Misdiagnosing the persistent vegetative state. Misdiagnosis certainly occurs [letter; comment]. BMJ 313(7062):944

Clauss RP, Nel WH (2004) Effect of zolpidem on brain injury and diaschisis as detected by $99 \mathrm{mTc}$ HMPAO brain SPECT in humans. Arzneimittelforschung 54(10):641-646

Clauss R, Nel W (2006) Drug induced arousal from the permanent vegetative state. NeuroRehabilitation 21(1):23-28

Clauss RP, Guldenpfennig WM, Nel HW et al (2000) Extraordinary arousal from semi-comatose state on zolpidem. A case report. S Afr Med J 90(1):68-72

Clauss R, Sathekge M, Nel W (2004) Transient improvement of spinocerebellar ataxia with zolpidem. N Engl J Med 351(5):511-512

Cochrane T (2006) Relevance of patient diagnosis of the Terri Schiavo case. Ann Intern Med 144 (4):305-306

Cohen SI, Duong TT (2008) Increased arousal in a patient with anoxic brain injury after administration of zolpidem. Am J Phys Med Rehabil 87(3):229-231

Daltrozzo J, Wioland N, Mutschler V et al (2007) Predicting coma and other low responsive patients outcome using event-related brain potentials: a meta-analysis. Clin Neurophysiol 118 (3):606-614

Damasio AR (1999) The feeling of what happens: body and emotion in the making of consciousness, 1st edn. Harcourt Brace, New York

Demertzi A, Vanhaudenhuyse A, Bruno MA et al (2008) Is there anybody in there? Detecting awareness in disorders of consciousness. Expert Rev Neurother 8(11):1719-1730

Demertzi A, Laureys, S, \& Bruno, MA (in press). The ethics in disorders of consciousness. In J. L. Vincent (Ed.), Yearbook of Intensive Care and Emergency Medicine. Berlin: Springer-Verlag

Demertzi, A., Ledoux, D., Bruno, M. A., Vanhaudenhuyse, A., Gosseries, O., Soddu, A., et al. (2011). Attitudes towards end-of-life issues in disorders of consciousness: a European survey. J Neurol, 258(6), 1058-1065

Deuschl G, Eisen A (1999) Recommendations for the practice of clinical neurophysiology: guidelines of the international federation of clinical neurophysiology. Elsevier, Amsterdam

Di HB, Yu SM, Weng XC et al (2007) Cerebral activation to patients' own name uttered by a familiar voice in the vegetative and minimally conscious states. Neurology 68(12):895-899

Dundon SJ (1978) Karen Quinlan and the freedom of the dying. J Value Inq 12(4):280-291

Fang S, Chan H, Chen W (2005) Combination of linear and nonlinear methods on electroencephalogram state recognition. Conf Proc IEEE Eng Med Biol Soc 5:4604-4605

Fins JJ (2003) Constructing an ethical stereotaxy for severe brain injury: balancing risks, benefits and access. Nat Rev Neurosci 4(4):323-327

Fins JJ, Illes J, Bernat JL et al (2008) Neuroimaging and disorders of consciousness: envisioning an ethical research agenda. Am J Bioeth 8(9):3-12

Fischer C, Luaute J, Adeleine P et al (2004) Predictive value of sensory and cognitive evoked potentials for awakening from coma. Neurology 63(4):669-673

Fridman EA, Krimchansky BZ, Bonetto M, Galperin T, Gamzu ER, Leiguarda RC, Zafonte R. Continuous subcutaneous apomorphine for severe disorders of consciousness after traumatic brain injury. Brain Inj. 2010;24(4):636-41

Giacino JT, Ashwal S, Childs N et al (2002) The minimally conscious state: definition and diagnostic criteria. Neurology 58(3):349-353

Giacino JT, Kalmar K, Whyte J (2004) The JFK coma recovery scale-revised: measurement characteristics and diagnostic utility. Arch Phys Med Rehabil 85(12):2020-2029 
Gill-Thwaites H (1997) The sensory modality assessment rehabilitation technique: a tool for assessment and treatment of patients with severe brain injury in a vegetative state. Brain Inj 11(10):723-734

Gosseries O, Bruno MA, Vanhaudenhuyse A et al (2009) Consciousness in the locked-in syndrome. In: Laureys S, Tononi G (eds) The neurology of consciousness: cognitive neuroscience and neuropathology. Academic Press Elsevier, Amsterdam

Guérit J-M, Mauguière F, Plouin P (2002) Guide pratique de neurophysiologie clinique. Recommandations de la Fédération internationale de neurophysiologie clinique. Elsevier, Amsterdam

Jennett B (2005) 30 years of the vegetative state: clinical, ethical and legal problems. In: Laureys S (ed) The boundaries of consciousness: neurobiology and neuropathology. Elsevier, Amsterdam

Jennett B, Plum F (1972) Persistent vegetative state after brain damage. A syndrome in search of a name. Lancet 1(7753):734-737

Kane NM, Curry SH, Rowlands CA et al (1996) Event-related potentials-neurophysiological tools for predicting emergence and early outcome from traumatic coma. Intensive Care Med 22 (1):39-46

Kubler A, Kotchoubey B (2007) Brain-computer interfaces in the continuum of consciousness. Curr Opin Neurol 20(6):643-649

Laureys S (2005) Science and society: death, unconsciousness and the brain. Nat Rev Neurosci 6(11):899-909

Laureys S, Boly M (2008) The changing spectrum of coma. Nat Clin Pract Neurol 4 (10):544-546

Laureys S, Fins JJ (2008) Are we equal in death? Avoiding diagnostic error in brain death. Neurology 70(4):e14-e15

Laureys S, Lemaire C, Maquet P et al (1999) Cerebral metabolism during vegetative state and after recovery to consciousness. J Neurol Neurosurg Psychiatry 67:121

Laureys S, Faymonville ME, Moonen G et al (2000a) PET scanning and neuronal loss in acute vegetative state. Lancet 355:1825-1826

Laureys S, Faymonville ME, Luxen A et al (2000b) Restoration of thalamocortical connectivity after recovery from persistent vegetative state. Lancet 355(9217):1790-1791

Laureys S, Faymonville ME, Lamy M (2000c) Cerebral function in vegetative state studied by positron emission tomography. In: Vincent JL (ed) 2000 yearbook of intensive care and emergency medicine. Springer, Berlin

Laureys S, Faymonville ME, Degueldre C et al (2000d) Auditory processing in the vegetative state. Brain 123(Pt 8):1589-1601

Laureys S, Majerus S, Moonen G (2002a) Assessing consciousness in critically ill patients. In: Vincent JL (ed) 2002 Yearbook of intensive care and emergency medicine. Springer, Heidelberg

Laureys S, Faymonville ME, Peigneux P et al (2002b) Cortical processing of noxious somatosensory stimuli in the persistent vegetative state. Neuroimage 17(2):732-741

Laureys S, van Eeckhout P, Ferring M et al (2003) Brain function in acute and chronic locked-in syndrome. Presented at the 9th annual meeting of the organisation for human brain mapping (OHBM), 18-22 June 2003, NY, USA, NeuroImage CD ROM Volume 19, Issue 2, Supplement 1

Laureys S, Owen AM, Schiff ND (2004a) Brain function in coma, vegetative state, and related disorders. Lancet Neurol 3(9):537-546

Laureys S, Perrin F, Faymonville ME et al (2004b) Cerebral processing in the minimally conscious state. Neurology 63(5):916-918

Laureys S, Pellas F, Van Eeckhout P et al (2005a) The locked-in syndrome: what is it like to be conscious but paralyzed and voiceless? Prog Brain Res 150:495-511

Laureys S, Perrin F, Schnakers C et al (2005b) Residual cognitive function in comatose, vegetative and minimally conscious states. Curr Opin Neurol 18(6):726-733

Laureys S, Boly M, Maquet P (2006a) Tracking the recovery of consciousness from coma. J Clin Invest 116(7):1823-1825 
Laureys S, Celesia G, Cohadon F, Lavrijsen J, Léon-Carrrion J, Sannita WG, Sazbon L, Schmutzhard E, von Wild KR, Zeman A, Dolce G Unresponsive wakefulness syndrome: a new name for the vegetative state or apallic syndrome and the European Task Force on Disorders of Consciousness BMC Medicine (2010) 8:68

Laureys S, Giacino JT, Schiff ND et al (2006b) How should functional imaging of patients with disorders of consciousness contribute to their clinical rehabilitation needs? Curr Opin Neurol 19(6):520-527

Leon-Carrion J, van Eeckhout P, Dominguez-Morales Mdel R et al (2002) The locked-in syndrome: a syndrome looking for a therapy. Brain Inj 16(7):571-582

Levy DE, Sidtis JJ, Rottenberg DA et al (1987) Differences in cerebral blood flow and glucose utilization in vegetative versus locked-in patients. Ann Neurol 22(6):673-682

Lin JS (2000) Brain structures and mechanisms involved in the control of cortical activation and wakefulness, with emphasis on the posterior hypothalamus and histaminergic neurons. Sleep Med Rev 4(5):471-503

Majerus S, Van der Linden M (2000) Wessex head injury matrix and Glasgow/Glasgow-Liège Coma Scale: a validation and comparison study. Neuropsychol Rehabil 10(2):167-184

Maquet P, Degueldre C, Delfiore G et al (1997) Functional neuroanatomy of human slow wave sleep. J Neurosci 17(8):2807-2812

Monti MM, Vanhaudenhuyse A, Coleman MR, Boly M, Pickard JD, Tshibanda L, Owen AM, Laureys S. Willful modulation of brain activity in disorders of consciousness. N Engl J Med. 2010 Feb 18;362(7):579-89. Epub 2010 Feb 3

Naatanen R, Alho K (1997) Mismatch negativity: the measure for central sound representation accuracy. Audiol Neurootol 2(5):341-353

Naccache L, Puybasset L, Gaillard R et al (2005) Auditory mismatch negativity is a good predictor of awakening in comatose patients: a fast and reliable procedure. Clin Neurophysiol 116(4):988-989

Nieuwenhuijs D, Coleman EL, Douglas NJ et al (2002) Bispectral index values and spectral edge frequency at different stages of physiologic sleep. Anesth Analg 94(1):125-129, Table of contents

Oh H, Seo W (2003) Sensory stimulation programme to improve recovery in comatose patients. J Clin Nurs 12(3):394-404

Owen AM, Coleman MR, Boly M et al (2006) Detecting awareness in the vegetative state. Science 313(5792): 1402

Passler MA, Riggs RV (2001) Positive outcomes in traumatic brain injury-vegetative state: patients treated with bromocriptine. Arch Phys Med Rehabil 82(3):311-315

Perrin F, Schnakers C, Schabus M et al (2006) Brain response to one's own name in vegetative state, minimally conscious state, and locked-in syndrome. Arch Neurol 63(4):562-569

Plum F, Posner JB (1983) The diagnosis of stupor and coma, 3rd edn. FA Davis, Philadelphia

Qin P, Di H, Yan X et al (2008) Mismatch negativity to the patient's own name in chronic disorders of consciousness. Neurosci Lett 448(1):24-28

Rappaport M (2000) The coma/near coma scale. The Center for Outcome Measurement in Brain Injury. Accessed 20 May 2009 from: http://www.tbims.org/combi/cnc

Schiff ND (2008) Central thalamic contributions to arousal regulation and neurological disorders of consciousness. Ann NY Acad Sci 1129:105-118

Schiff ND, Rodriguez-Moreno D, Kamal A et al (2005) fMRI reveals large-scale network activation in minimally conscious patients. Neurology 64(3):514-523

Schiff ND, Giacino JT, Kalmar K et al (2007) Behavioural improvements with thalamic stimulation after severe traumatic brain injury. Nature 448(7153):600-603

Schnakers C, Majerus S, Laureys S (2004) Diagnosis and investigation of altered states of consciousness. Reanimation 13:368-375

Schnakers C, Majerus S, Laureys S et al (2005) Neuropsychological testing in chronic locked-in syndrome. Psyche, abstracts from the 8th conference of the association for the scientific study of consciousness (ASSC8), 11(1), University of Antwerp, Belgium, 26-28 June 2004 
Schnakers C, Majerus S, Laureys S (2005b) Bispectral analysis of electroencephalogram signals during recovery from coma: preliminary findings. Neuropsychol Rehabil 15(3-4):381-388

Schnakers C, Giacino J, Kalmar K et al (2006) Does the FOUR score correctly diagnose the vegetative and minimally conscious states? Ann Neurol 60(6):744-745

Schnakers C, Majerus S, Giacino J, Vanhaudenhuyse A, Bruno MA, Boly M, Moonen G, Damas P, Lambermont B, Lamy M, Damas F, Ventura M, Laureys S (2008) A French validation study of the Coma Recovery Scale-Revised (CRS-R). Brain Inj. Sep;22(10):786-92

Schnakers C, Ledoux D, Majerus S et al (2008a) Diagnostic and prognostic use of bispectral index in coma, vegetative state and related disorders. Brain Inj 22(12):926-931

Schnakers C, Perrin F, Schabus M et al (2008b) Voluntary brain processing in disorders of consciousness. Neurology 71(20):1614-1620

Schnakers C, Hustinx R, Vandewalle G et al (2008c) Measuring the effect of amantadine in chronic anoxic minimally conscious state. J Neurol Neurosurg Psychiatry 79(2):225-227

Schnakers C, Perrin F, Schabus M et al (2009) Detecting consciousness in a total locked-in syndrome: an active event-related paradigm. Neurocase 15(4):271-277

Sellers E, Kübler A, Donchin E (2006) Brain-computer interface research at the University of South Florida Cognitive Psychophysiology Laboratory: the P300. IEEE Trans Neural Syst Rehabil Eng 14(2):221-224

Shames JL, Ring H (2008) Transient reversal of anoxic brain injury-related minimally conscious state after zolpidem administration: a case report. Arch Phys Med Rehabil 89(2):386-388

Shiel A, Horn SA, Wilson BA et al (2000) The Wessex head injury matrix (WHIM) main scale: a preliminary report on a scale to assess and monitor patient recovery after severe head injury. Clin Rehabil 14(4):408-416

Shiel A, Burn JP, Henry D et al (2001) The effects of increased rehabilitation therapy after brain injury: results of a prospective controlled trial. Clin Rehabil 15(5):501-514

Sorger B, Dahmen B, Reithler J, Gosseries O, Maudoux A, Laureys S, Goebel R (2009) Another kind of 'BOLD Response:' answering multiple-choice questions via online decoded singletrial brain signals Progress in Brain Research, 177 (2009) 275-292, vs/sorger_PBR_coma_science_2009.pdf

Struys M, Versichelen L, Mortier E et al (1998) Comparison of spontaneous frontal EMG, EEG power spectrum and bispectral index to monitor propofol drug effect and emergence. Acta Anaesthesiol Scand 42(6):628-636

Sutton S, Braren M, Zubin J et al (1965) Evoked-potential correlates of stimulus uncertainty. Science 150(700): 1187-1188

Taira T, Hori T (2007) Intrathecal baclofen in the treatment of post-stroke central pain, dystonia, and persistent vegetative state. Acta Neurochir Suppl 97(Pt 1):227-229

Teasdale G, Jennett B (1974) Assessment of coma and impaired consciousness. A practical scale. Lancet 2(7872):81-84

The Multi-Society Task Force on PVS (1994) Medical aspects of the persistent vegetative state (1). N Engl J Med 330(21):1499-1508

The Quality Standards Subcommittee of the American Academy of Neurology (1995) Practice parameters for determining brain death in adults (summary statement). Neurology 45 (5):1012-1014

Tolle P, Reimer M (2003) Do we need stimulation programs as a part of nursing care for patients in "persistent vegetative state"? A conceptual analysis. Axone 25(2):20-26

van der Stelt O, van Boxtel GJ (2008) Auditory P300 and mismatch negativity in comatose states. Clin Neurophysiol 119(10):2172-2174

Vanhaudenhuyse A, Bruno MA, Bredart S et al (2007) The challenge of disentangling reportability and phenomenal consciousness in post-comatose states. Brain Behav Sci 30:529-530

Vanhaudenhuyse A, Giacino J, Schnakers C et al (2008a) Blink to visual threat does not herald consciousness in the vegetative state. Neurology 71(17):1374-1375 
Vanhaudenhuyse A, Schnakers C, Bredart S et al (2008b) Assessment of visual pursuit in postcomatose states: use a mirror. J Neurol Neurosurg Psychiatry 79(2):223

Vanhaudenhuyse A, Laureys S, Perrin F (2008c) Cognitive event-related potentials in comatose and post-comatose states. Neurocrit Care 8(2):262-270

Vanhaudenhuyse A, Boly M, Laureys S (2009) Vegetative state. Scholarpedia 4:4163

Voss HU, Uluc AM, Dyke JP et al (2006) Possible axonal regrowth in late recovery from the minimally conscious state. J Clin Invest 116(7):2005-2011

Wade DT (1996) Misdiagnosing the persistent vegetative state. Persistent vegetative state should not be diagnosed until 12 months from onset of coma [letter; comment]. BMJ 313(7062):943-944

Whyte J, DiPasquale MC (1995) Assessment of vision and visual attention in minimally responsive brain injured patients. Arch Phys Med Rehabil 76(9):804-810

Whyte J, DiPasquale MC, Vaccaro M (1999) Assessment of command-following in minimally conscious brain injured patients. Arch Phys Med Rehabil 80(6):653-660

Whyte J, Katz D, Long D et al (2005) Predictors of outcome in prolonged posttraumatic disorders of consciousness and assessment of medication effects: a multicenter study. Arch Phys Med Rehabil 86(3):453-462

Whyte J, Myers R Incidence of clinically significant responses to zolpidem among patients with disorders of consciousness: a preliminary placebo controlled trial. Am J Phys Med Rehabil. 2009 May;88(5):410-8

Wijdicks EF (2001) The diagnosis of brain death. N Engl J Med 344(16):1215-1221

Wijdicks E (2006) Minimally conscious state vs. persistent vegetative state: the case of Terry (Wallis) vs. the case of Terri (Schiavo). Mayo Clin Proc 81(9):1155-1158

Wijdicks EF, Bamlet WR, Maramattom BV et al (2005) Validation of a new coma scale: the FOUR score. Ann Neurol 58(4):585-593

Wilhelm B, Jordan M, Birbaumer N (2006) Communication in locked-in syndrome: effects of imagery on salivary $\mathrm{pH}$. Neurology 67(3):534-535

Wood RL, Winkowski TB, Miller JL et al (1992) Evaluating sensory regulation as a method to improve awareness in patients with altered states of consciousness: a pilot study. Brain Inj $6(5): 411-418$

Young GB (2000) The EEG in coma. J Clin Neurophysiol 17(5):473-485

Zafonte RD, Lexell J, Cullen N (2000) Possible applications for dopaminergic agents following traumatic brain injury: part 1. J Head Trauma Rehabil 15(5):1179-1182

Zandbergen EG, de Haan RJ, Stoutenbeek CP et al (1998) Systematic review of early prediction of poor outcome in anoxic-ischaemic coma. Lancet 352(9143):1808-1812

Zeman A (2001) Consciousness. Brain 124(Pt 7):1263-1289 